\title{
Transient Non-Ketotic Hyperglycinemia in a Newborn
}

\author{
Choudhury $\mathbf{T}^{1}$, Kundu $\mathrm{S}^{2}$, Das $\mathrm{GC}^{3}$, Dasgupta $\mathrm{MK}^{4}$
}

${ }^{1}$ Dr. Tarak Choudhury, Junior Resident, ${ }^{2} \mathrm{Dr}$. Soumi Kundu, Junior Resident, ${ }^{3}$ Professor GC Das, ${ }^{4}$ Professor Malay Kumar Dasgupta. All from the Department of Paediatrics, RG Kar Medical College, Kolkata, West Bengal, India.

\section{Address for correspondence: \\ Dr. Tarak Choudhury \\ E-mail: tarakchoudhury6@gmail.com}

\section{How to cite}

Choudhury T, Kundu S, Das GC, Dasgupta MK. Transient Non-Ketotic Hyperglycinemia in a Newborn. J Nepal Paediatr Soc 2016;36(3):303-306.

doi: http://dx.doi.org/10.3126/jnps.v36i3.16047

This work is licensed under a Creative Commons Attribution 3.0 License.

\begin{abstract}
In encephalopathic infants, cerebrospinal fluid hyperglycinemia and elevated cerebrospinal fluid to plasma glycine ratio are considered pathognomonic of Non-ketotic hyperglycinemia(NKH). It is due to a defect of the glycine cleavage system and has poor prognosis. We present a case of transient $\mathrm{NKH}$ presented to us with hypotonia,recurrent apnea and seizure. Increased ratio of cerebrospinal fluid to plasma glycine concentrations of 0.16 was seen as a strong diagnostic indicator of Non-ketotic hyperglycinemia.
\end{abstract}

\section{Introduction}

Iycine encephalopathy, also known as Nonketotic hyperglycinemia $(\mathrm{NKH})$, is an inborn error of glycine metabolism caused by deficiency in the glycine cleavage system (GCS) ${ }^{1}$ and is characterized by large quantities of glycine accumulated in all body tissues, especially in serum and cerebrospinal fluids. Non-ketotic hyperglycinemia $(\mathrm{NKH})$ is an inborn error of glycine degradation, which causes hypotonia, lethargy, apnea, seizures,myoclonic jerks and hiccups ${ }^{2,3}$.Outcome is usually poor, with mortality up to $50 \%$ during the first week of life. Surviving infants have profound intellectualdisability and intractable seizures. Atypical forms includemilder disease, with onset from late infancy to adulthood, which presents various neurological symptoms: seizure, motor and/or cognitive impairments, aggressive behavior, andimpaired work or school performance ${ }^{4}$.

A Rare transient form has been described in which newborns have elevated cerebrospinal fluid and plasma glycine, which is biochemically and clinically indistinguishable from the classic form. In the rare form, glycine levels normalize over time without pharmacologic intervention and often have few or no neurologic sequelae ${ }^{5}$. We present a case sick neonate(19 days old) with features of hypotonia,apnoea,seizures which was later diagnosed to be transient non-ketotichyperglycinemia by measuring CSF and plasma glycine value.

We present a case of $\mathrm{NKH}$ presented in neonatal period with recurrent apnea and seizures. Evaluating a sick neonate who presents with hypotonia,apnoeaencephalopathy, and seizures is a diagnostic challenge; a high index of suspicion for timely diagnosis and treatment could prevent severe complications. 


\section{The Case}

A 19 days old male child (Figure 1) admitted in our hospital with recurrent episodes of apnea and seizures. The baby was a term/SGA/LBW(1800gms), born of non-consanguineous marriage. Pregnancy was uneventful, labor and delivery were uncomplicated. The length of baby was $48 \mathrm{~cm}$ and head circumference was $32 \mathrm{~cm}$. Physical examination shows presence of cyanosis. Gastrointestinal examination reveals no Hepatosplenomegaly.Neonatal reflex such as rooting,sucking, ATNR and Moro's reflex were absent. On cranial nerve examination pupils are bilateral equal and reacting to light with no facial muscle weakness and no gag reflex. The baby was lying in frog like position with gross hypotonia of axial and appendicular muscles. Knee jerk was absent and other jerks could not be elicited.

As the baby developed recurrent episodes of apnea,the baby was put on ventilator. The patient developed seizure activity. After checking the blood glucose $(82 \mathrm{mg} / \mathrm{dl})$ and calcium(9.5 mg/dl) which was normal we gave Inj.Phenobarbitoneafter which the convulsion was controlled. Investigation showed complete blood count(TLC-8200, ANC-4100, I/T RATIO- 0.07),CRP-negative, Blood culture report shows no growth. CSF examination showed five lymphocytes. Protein and sugar were normal.ABG report was normal and there were no features of acidosis. Urine test for reducing substance was absent. Blood report for Sodium, potassium and calcium were also normal. MRI of brain revealed no abnormality.

So we suspected unusual cause of apnea by some metabolic disorder. As there was no hepatosplenomegaly and urine test for reducing substance was negative so we ruled out glycogen storage disease. We suspect amino acid metabolism disorder. So we sent plasma and CSF of the baby to biochemistry for amino acid estimation. The report showed that there was increased amount of glycine in both plasma and CSF. Lab. values were; Plasma glycine: 264.59(2.00- 745.00), CSF Glycine: $43.61 \mu \mathrm{mol} / \mathrm{L}(5-40 \mu \mathrm{mol} / \mathrm{L})$ and CSF:Plasma glycine ratio was 0.16 .

The patient was weaned off from ventilator after five days and thereafter no further episode of apnea occurred and we discharged the patient on the $10^{\text {th }}$ day. Regular follow-up was done every week up to two months and baby was absolutely normal. At the end of two months we again sent plasma and CSF samples for glycine value study and it was found that plasma glycine was $340.06 \mu \mathrm{mol} / \mathrm{L}$ and CSF glycine was 30.2 $\mu \mathrm{mol} / \mathrm{L}$. CSF to plasma glycine ratio was found to be 0.8.So as there was no further episode of apnea and seizure activity and the growth and development of baby was absolutely normalour final diagnosis was a case of transient $\mathrm{NKH}$.

\section{Discussion}

When a patient presents with recurrent episodes of apnea and seizure activity on 3rd week of life we have to consider sepsis, apnoea of prematurity, CNS infection,electrolyte disturbances, metabolic disorder. In this case as the baby was term and an uneventful perinatal history apnea of prematurity was ruled out. Sepsis screen and CSF examination was normal so sepsis was ruled out. Electrolytes were normal, ABG report was normal and no acidosis present. Ultrasonography and MRI reveals no abnormality so brain malformation was also ruled out. Thus we suspected amino acid metabolism disorder and subsequently diagnosed it as a case of non-ketotic hyperglycinemia.

$\mathrm{NKH}$ is an autosomal recessive metabolic disorder characterizedby glycine accumulating in the brain due to defective Glycine Cleavage System. Incidence of glycine encephalopathy in British Columbia is 1:63,000 live births and 1:55,000 newborns in Finland ${ }^{6}$. Classically, $\mathrm{NKH}$ is associated with normal pregnancy and birth, then presented with neonatal apnea, lethargy, hypotonia and seizures followed by severe psychomotor retardation in those who survive. In the laboratory test, $\mathrm{NKH}$ is characterized by elevated glycine concentrations in plasma, CSF, and brain with a CSF glycine to plasma glycine ratio greater than 0.08 , which is diagnostic. A ratio of $>0.04$ is suggestive but require further confirmation through enzymatic analysis of liver or mutation detection. In our case, glycine CSF/plasma ratio was 0.16 , elevated cerebrospinal fluid glycine is reported in infants with encephalopathy: e.g hypoxic ischemic encephalopathy, congenital stroke, central nervous system infection ${ }^{7}$.

Non-ketotic hyperglycinemia, classified as neonatal, infantile, late onset and transient based on its clinical course, is a very rare autosomal recessively inherited disease. The metabolic defect of $\mathrm{NKH}$ is in the glycine cleavage system (GCS), a complex enzyme system with four components: the $\mathrm{P}$, the $\mathrm{H}$, the $\mathrm{T}$, and the $L$ protein ${ }^{8}$.Most patients with the neonatal type have a defect in the

$P$ protein. Later-onset cases have been thought to have defects in the $\mathrm{H}$ or $\mathrm{T}$ protein. Due to deficient activity of the GCS, the major pathway for the catabolism 
of glycine, large quantities of glycine accumulate in all body tissues. High concentrations of glycine in the central nervous system Produce excito-neurotoxicity, seizure and brain damage, through the overstimulation of the N-methyl-Aspartic acid (NMDA) receptor, via an action at the associated glycine modulatory site $^{8}$. Glycine is inhibitory in the spinal cord and brain stem and this may be responsible for the apnea seen in the disease.

The typical neonatal form presents in the first few days after birth with progressive lethargy, hypotonia, hiccups, and seizures then progresses to central apnea, and often death. Surviving infants have profound developmental delay and intractable seizures. The infantile form occurs in the first few months of life and is also characterized by hypotonia, developmental delay, and seizures. Increased CSF glycine level (typically 20-30 times normal) along with elevated CSF/plasma glycine ratio, suggests diagnosis. Gold standard for diagnosis is still liver biopsy, but this is not feasible in many cases. A noninvasive C-glycine breath test and screening system for genomic deletion with GLDC also help confirm diagnosis ${ }^{9,10}$. Genes known to associate with $\mathrm{NKH}$ are GLDC(encoding P-protein component ofthe GCS complex), AMT (encoding T-protein component), and GCSH (encoding H-protein component). Molecular genetic testing of all three genes is available on a clinical basis. Mutations associated with residual enzyme activity seem associated with a milder outcome and infantile presentation; two mutationswith

\section{References}

1. Tada K, Narisawa K, Yoshida T, Konno T, Yokoyama Y.Hyperglycinemia: a defect in glycine cleavage reaction. Tohoku J Exp Med 1969;98:289e96.

2. Coßkun T,.zalp I, M.nch E, Yalaz K.Nonketotic hyperglycinemia. Turk JPediatr1988;30: 271-9.

3. Tekinalp G, Coskun T, Oran O,.zalpl,Figen G, Ergin $\mathrm{H}$. Nonketotichyperglycinemiain a newborn infant. Turk JPediatr1995;37:57-60.

4. Hoover-Fong JE, Shah S, Van Hove JL, Applegarth D, Toone J Hamosh A. Natural history of nonketotic hyperglycinemia in65 patients. Neurology 2004;63:847e53.

5. Aliefendioglu D, Tana Aslan A, Cos,kun T, Dursun A,Cakmak FN, Kesimer M. Transient nonketotichyperglycinemia: two case reports and literature review.PediatrNeurol 2003;28:151e5

6. Applegarth DA, Toone JR, Lowry RB. Incidence of inbornerrors of metabolism in British Columbia, 19691996. Pediatrics 2000;105:10. no residual enzyme activity seem linked with severe outcome and neonatal onset ${ }^{11,12}$. MRI can show normal, agenesis of the corpus callosum, delay in myelination, vacuolation, gliosis, or, less frequently, retrocerebellar cysts with subsequent hydrocephalus ${ }^{13,14}$. To date, no effective treatment exists for $\mathrm{NKH}$. The standard treatment strategies for $\mathrm{NKH}$ include sodium benzoate (to reduce plasma concentration of glycine) and NMDA receptor antagonists (ketamine, dextromethorphan, felbamate, andtopiramate $)^{15}$.Others focus on seizure control with antiepileptic drugs. Among AEDs, valproate should be avoided in glycine encephalopathy, since it raises blood and CSF glycine concentrations by further inhibiting the GCS and may increase seizure frequency ${ }^{16}$.In our case only symptomatic treatment was given as it was a case of transient $\mathrm{NKH}$ and the growth and development was absolutely normal after the episode.

\section{Conclusion}

Transient NKH should be considered as a differential diagnosis for cases presented with hypotonia,recurrent apnea and seizures. But it is a rare disease and very few cases have been reported in review of literature. Hence this case is reported.Evaluating sick neonates with hypotonia, encephalopathy, apnea, and/or seizures is a diagnostic challenge. $\mathrm{NKH}$ should beconsidered in a term baby; elevated cerebrospinal fluid/plasma glycine ratio will allow correct identification and treatment more often in the future.

7. Joseph J. Volpe. Neurology of the newborn. 5th ed. 2008. Sunders, p. 659e67.

8. KureS,TadaK, NarisawaK. Nonketotichyperglycinemia: biochemical, molecular, and neurological aspects. Jpn JHum Genet1997;42(1):13-22.

9. Kure S, Kato K, Dinopoulos A, Gail C, DeGrauw TJ,Christodoulou J, et al. Comprehensive mutation analysis ofGLDC, AMT, and GCSH in nonketotic hyperglycinemia. HumMutat 2006;27:343e52.

10. Kure S, Korman SH, Kanno J, Narisawa A, Kubota $\mathrm{M}$, Takayanagi $\mathrm{T}$, et al. Rapid diagnosis of glycine encephalopathyby 13C-glycine breath test. Ann Neurol 2006;59:862e7

11. Suzuki $Y$, Kure $S$, Oota $M$, Hino $H$, Fukuda $M$. Nonketotichyperglycinemia: proposal of a diagnostic and treatmentstrategy. PediatrNeurol 2010;43:221e4.

12. Kikuchi G, Motokawa $\mathrm{Y}$, Yoshida T, Hiraga K. Glycinecleavage system: reaction mechanism, physiological significance, and hyperglycinemia. Proc JpnAcadSer B PhysBiolSci 2008;84:246e63. 
13. Mourmans J, Majoie CB, Barth PG, Duran M AkkermanEM,Poll-The BT. Sequential MR imaging changes in nonketotichyperglycinemia. AJNR Am J Neuroradiol 2006;27:208e11.

14. Viola A, Chabrol B, Nicoli F, Confort-Gouny $\mathrm{S}$, VioutP,Cozzone PJ. Magnetic resonance spectroscopy study ofglycine pathways in nonketotic hyperglycinemia. Pediatr Res2002;52:292e300.
15. Van Hove JL, VandeKerckhove K, Hennermann JB, MahieuV,Declercq $P$, Mertens $S$, et al. Benzoate treatment and theglycine index in nonketotichyperglycinaemia. J InheritMetab Dis 2005;28:651e63.

16. Morrison PF, Sankar R, Shields WD. Valproateinducedchorea and encephalopathy in atypical nonketotichyperglycinemia.

PediatrNeurol 2006;35:356e8 